\title{
The impact of feed additives on the microbial ecology of the gut in young pigs
}

\author{
B. B. Jensen \\ Danish Institute of Agricultural Sciences, \\ Department of Animal Nutrition and Physiology, Research Centre Foulum \\ 8830 Tjele, Denmark
}

\section{ABSTRACT}

The diverse collection of microorganisms colonising the healthy gastrointestinal tract of pigs, referred to as the microbiota, plays an essential role not only for the well-being of the animal, but also for animal nutrition and performance and for the quality of animal products. A number of naturally-occurring and artificial factors has been shown to affect the composition and activity of the microbiota in the gastrointestinal tract of pigs, these include: diet composition, growth promoting antibiotics, copper, use of probiotics, specific carbohydrates, organic acids and fermented feed.

It is generally accepted that the microbiota in the small intestine competes with the host animal for easily digestible nutrients and at the same time produces toxic compounds. A pronounced microbial fermentation occurs in the stomach and small intestine in young piglets. Results have shown that approximately equal amounts of organic acids were produced in the three compartments: stomach, small intestine and large intestine. Further, experiments have shown that as much as $6 \%$ of the net energy in the pig diet could be lost due to microbial fermentation in the stomach and small intestine. On the other hand it has been shown that on a normal Danish pig diet, $16.4 \%$ of the total energy supply for the pig is achived from microbial fermentation in the large intestine. However, the microbiota in the gastrointestinal tract is unstable the first week after weaning and it takes 2 to 3 weeks after weaning before the fermentation capacity of the microbiota in the hindgut has developed.

Use of growth promoting antibiotics in the feed is widespread in pig production. However, the use of the antibiotics avoparcin and virginiamycin as growth promoters in animal feed has been associated with an increase in resistance of bacteria to therapeutic agents and a fear that this could reduce the ability to treat diseased humans. This has caused an increased awareness of the use of antibiotics and a general wish to reduce the use of antibiotic growth promoters.

Probiotics, organic acids and specific carbohydrates (yeast cell walls) are often suggested as alternatives to the use of antibiotic growth promoters. However, due to their relative high prices and the variability and unpredictability of their effect, the use of these products is financially questionable in practical pig production. One way to solve this problem may be the use of fermented liquid feed. Fermented liquid feed is characterised by a high number of lactic acid bacteria, high number of yeast and high concentration of lactic acid, and several investigations has shown fermented liquid 
feed to improve growth performance in pigs and to established a prophylactic barrier against gastrointestinal disorders. In general there is no doubt that the effect of feed additives are greatest in young animals where they have been found to improve growth performance and to reduce scouring and neonatal mortality. The present paper review our current state of knowledge about how various feed additives affect the gastrointestinal ecosystem.

KEY WORDS: microbial ecology, young pigs, feed additives

\section{INTRODUCTION}

Promotion of animal health and increase in growth performance, via manipulation of the microbial activity in the gastrointestinal tract of monogastric animals, has become an area of intense commercial exploitation. A formidable array of feed additives, claimed to improve pig performance through an effect on the gut ecosystem, is available to the feed compounder and the pig producer. These range from chemicals such as antibiotics and organic acids to biological products such as probiotics and antibodies. In reality, the only factor these various groups of products have in common is the variability and unpredictability of their effects. Even the most successful of the additives, the antibiotics, which have been in use for almost fifty years, are ineffective almost as often as they are effective, and furthermore their mode of action still remains to be fully clarified. This could lead to the conclusion that the available products are generally of marginal benefit. An equally plausible argument, however, could be that the claims for the products are inappropriate and give rise to false expectations. Similarly, it could be contended that the appropriate conditions for the use of the feed additives are poorly defined. As pointed out by Chesson (1994), intestinal mediators may have two closely related but not synonymous effects; 1 . growth promoting effects through improved efficiency of feed conversion and/or intake, and 2. the establishment of a prophylactic barrier against gastrointestinal disorders. There is no doubt that the effects of feed additives are greatest in young animals - where they have been found to improve growth performance and to reduce scouring and neonatal mortality. The objective of the present paper is to review our current state of knowledge about how feed additives affect the gastrointestinal ecosystem.

\section{DEVELOPMENT OF THE MICROBIOTA IN YOUNG PIGS}

At birth, the young pig which is axenic during its utcrine life is suddenly confronted with a complex bacterial environment. The major source of bacteria for the new-born pig is the maternal faeces. The piglet not only acquires bacteria from 
the sows faecally contaminated vagina and perineum during birth, but also from the skin and teats of the sow which are usually contaminated as well (Arbuckle, 1968). In addition, it has been conclusively demonstrated by Gleed and Sansom (1982) that from the first day of life and throughout the suckling period piglets ingest considerable quantities of their mothers faeces.

The population level of the microbiota in the various parts of the gastrointestinal tract of monogastric animals, depends on the replication time of the microorganism under the physicochemical conditions and emptying rhythm in that part of the gastrointestinal tract under investigation. In pigs, the stomach is the first reservoir where the ingesta spend some time, and where the microbiota may multiply. At birth, the stomach of the new-born pig is sterile (Sinkovics and Juhasz, 1974) but within 2-3 h viable organisms of at least four different groups of bacteria (lactobacilli, streptococci, coliform bacteria and clostridia) can be isolated from gastric contents. The population of these bacteria groups increases rapidly during the first 24 to $48 \mathrm{~h}$. In the subsequent 5-6 days, lactobacilli and streptococci become the dominant groups with densities reaching $10^{7}-10^{9}$ viable organisms per g digesta. The lactobacilli and streptococci remain the dominant group of microbiota in the gastric content during the remainder of the suckling period. These permanent populations can be achieved in the stomach of the piglets because the bacteria associate with the stratified squamous epithelium surface of the pars oesophagea (the region of the stomach which surrounds the cardiac opening). Being non-secretory, the squamous epithelium is not covered by a layer of mucus, and lactobacilli and streptococci can adhere to the epithelial cells. The pars oesophagea comprises approximately $5 \%$ of the surface area of the stomach (Cranwell, 1990). The stratified squamous epithelium of the pars oesophagea undergoes continuous desquamation. Furthermore, as already pointed out by Fuller et al. (1978), the release of these epithelial cells and their associated bacteria is an important mechanism for regulating the composition of the stomach microbiota - by supplying a continuous innoculum of specific lactobacilli and streptococci to the feed as it enters the stomach, thus ensuring the dominance of lactic acid bacteria in the gastric content.

In contrast to the stomach, the proximal part of the small intestine is no place for bacterial proliferation in healthy pigs, simply because the intestinal transit time is too rapid to allow time for microbial division. Proliferation occurs in the upper part of the small intestine (with pathological consequences), only when there is adhesion to the gut wall, or mechanical obstruction leading to stasis of digesta. Alimentary stasis is the rule in the distal part of the small intestine, and this results in a large microbial population. The pattern and nature of early development of the microbiota in the small intestine is similar to that which occurs in the stomach. Throughout the suckling period lactobacilli and streptococci remain the dominant groups of organisms in the small intestine. 
Published information about the populations of different groups of bacteria in caecal and colonic contents of pigs has been summarised by Cranwell (1990). It is evident that there is considerable variation in the counts of all groups of organisms, both within each study and between studies. Whereas this may well illustrate the natural variation in the bacterial numbers which occurs in the large intestine it also indicates the differences which occur when different isolation and enumeration techniques are used and the difficulties in working with strict anaerobic microorganisms. Although a detailed study of the bacterial composition in the hind gut of young pigs is missing there is no doubt that the hydrolytic digestive function of the large intestine of young pigs is carried out by a rich and diverse population of anaerobic bacteria, many of which are yet to be described.

\section{EFFECT OF WEANING}

In nature, weaning is a slow process, but modern production methods often involve very early and sudden weaning, which can enhance susceptibility to diseases. Several studies have investigated the changes in the gut ecosystem of pigs in relation to weaning (Wilbur et al., 1960; Risley et al., 1992; Katouli et al., 1997).
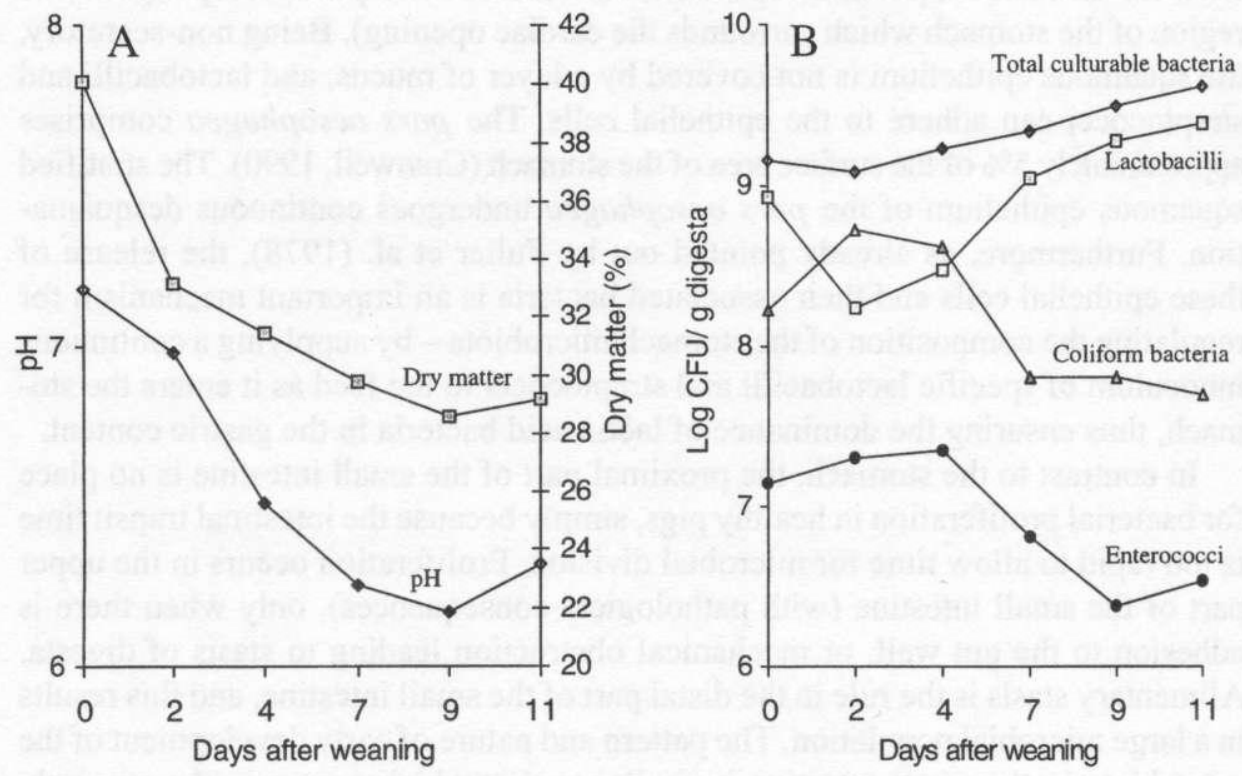

Figure 1. Changes in $\mathrm{pH}$ and dry matter content (A) and selected bacterial groups (B) in rectal samples of pigs before weaning, at 28 days and the first 11 days postweaning. Each point represents the mean value from 18 pigs 
The changes in dry matter and the densities of selected bacterial groups in rectal samples from 18 pigs before weaning, at 28 days and for the first 11 days after weaning, from an experiment carried out by Jensen (unpublished), are shown in Figure 1. A steady decrease in $\mathrm{pH}$ and dry matter content was observed during the first week postweaning. The population of lactobacilli declined just after weaning (d 2 and 4 postweaning) but then increased from day 7 postweaning. Concurrently, coliform counts were generally greater on day 2 and 4 postweaning, indicating an inverse connection between lactobacilli and coliform bacteria during the first week after weaning. This tends to make the pig susceptible to scouring and poor growth performance. Similar results have been reported by Risley et al. (1992).

The change in $\mathrm{pH}$, dry matter, amount of gut content and microbial activity (ATP concentration) in various regions of the gastrointestinal tract in pigs sacrificed at weaning (28 days), 6 days after weaning and 20 days after weaning is shown in Figure 4. Similar results for the composition of various bacterial populations in gut content and attached to the gut epithelium are shown in Figures 2 and 3.
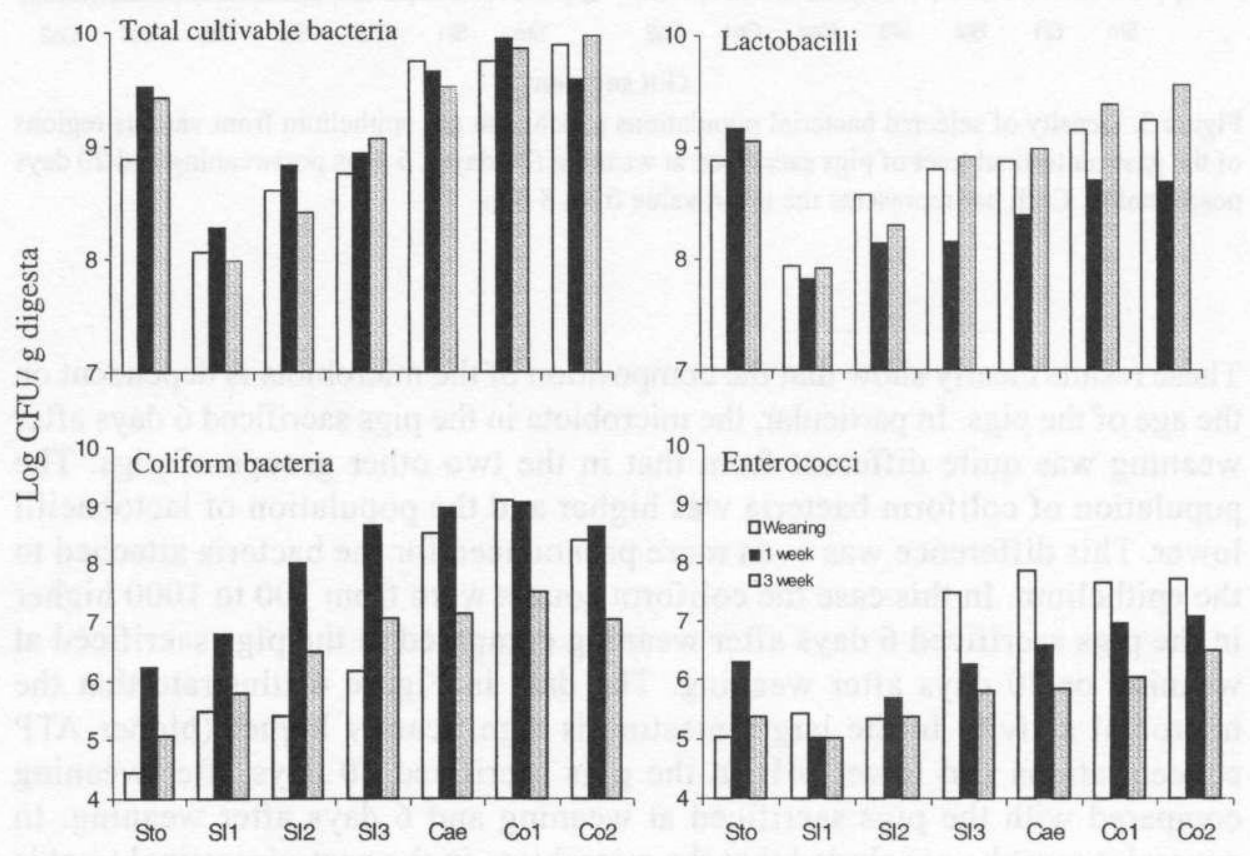

Gut segment

Figure 2. Density of selected bacterial populations in gut content from various regions of the gastrointestinal tract of pigs sacrificed at weaning ( 28 days), 6 days postweaning and 20 days postweaning. Each bar represents the mean value from 8 pigs 

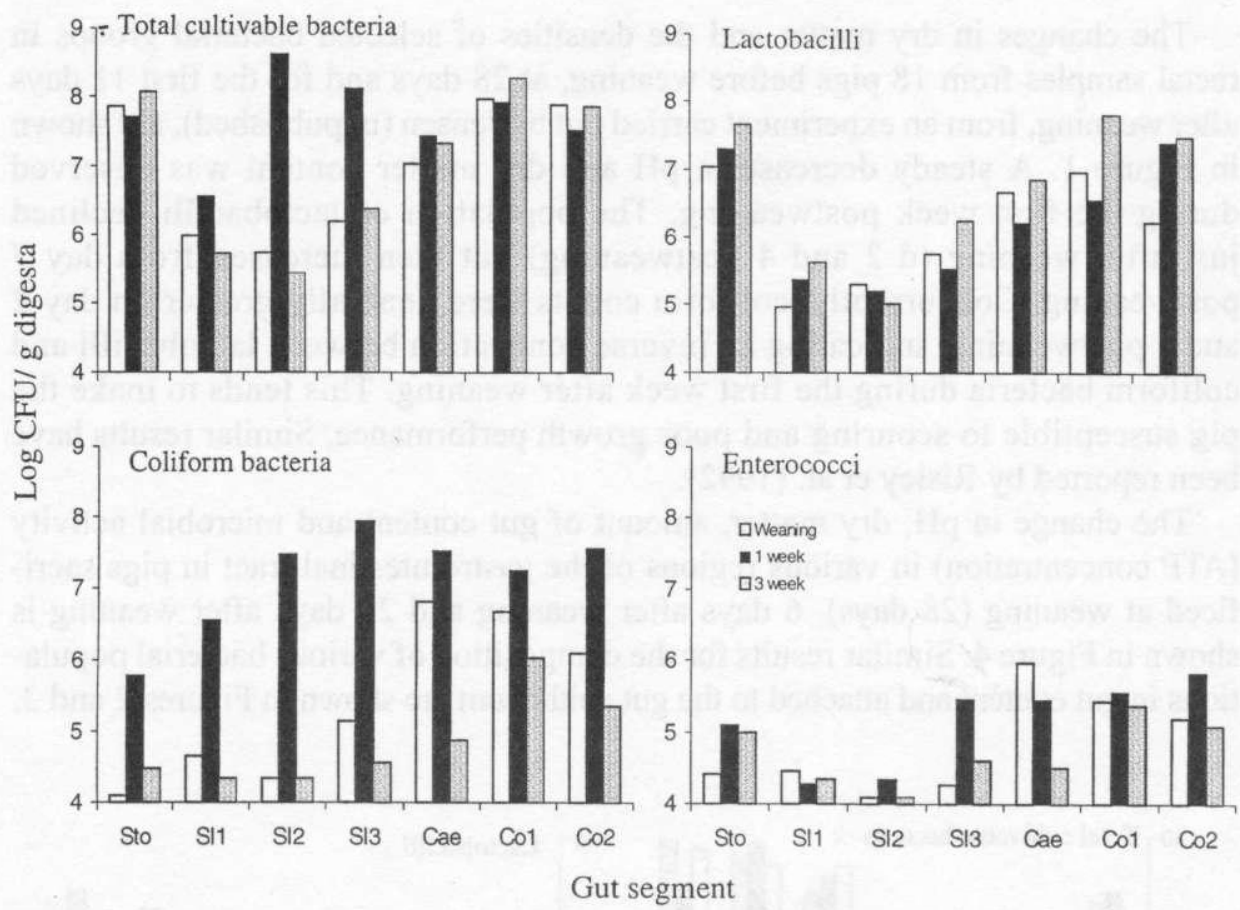

Figure 3. Density of selected bacterial populations attached to gut epithelium from various regions of the gastrointestinal tract of pigs sacrificed at weaning (28 days), 6 days postweaning and 20 days postweaning. Each bar represents the mean value from 8 pigs

These results clearly show that the composition of the microbiota is dependent on the age of the pigs. In particular, the microbiota in the pigs sacrificed 6 days after weaning was quite different from that in the two other groups of pigs. The population of coliform bacteria was higher and the population of lactobacilli lower. This difference was even more pronounced for the bacteria attached to the epithelium. In this case the coliform counts were from 100 to 1000 higher in the pigs sacrificed 6 days after weaning compared to the pigs sacrificed at weaning or 20 days after weaning. The data in Figure 4 illustrate that the microbial activity in the large intestine is significantly higher (higher ATP concentrations and lower $\mathrm{pH}$ ) in the pigs sacrificed 20 days after weaning compared with the pigs sacrificed at weaning and 6 days after weaning. In general it must be concluded that the microbiota in the gastrointestinal tract is unstable during the first week postweaning and that it takes 2 to 3 weeks after weaning before the fermentative capacity of the microbiota in the hind gut has developed. 

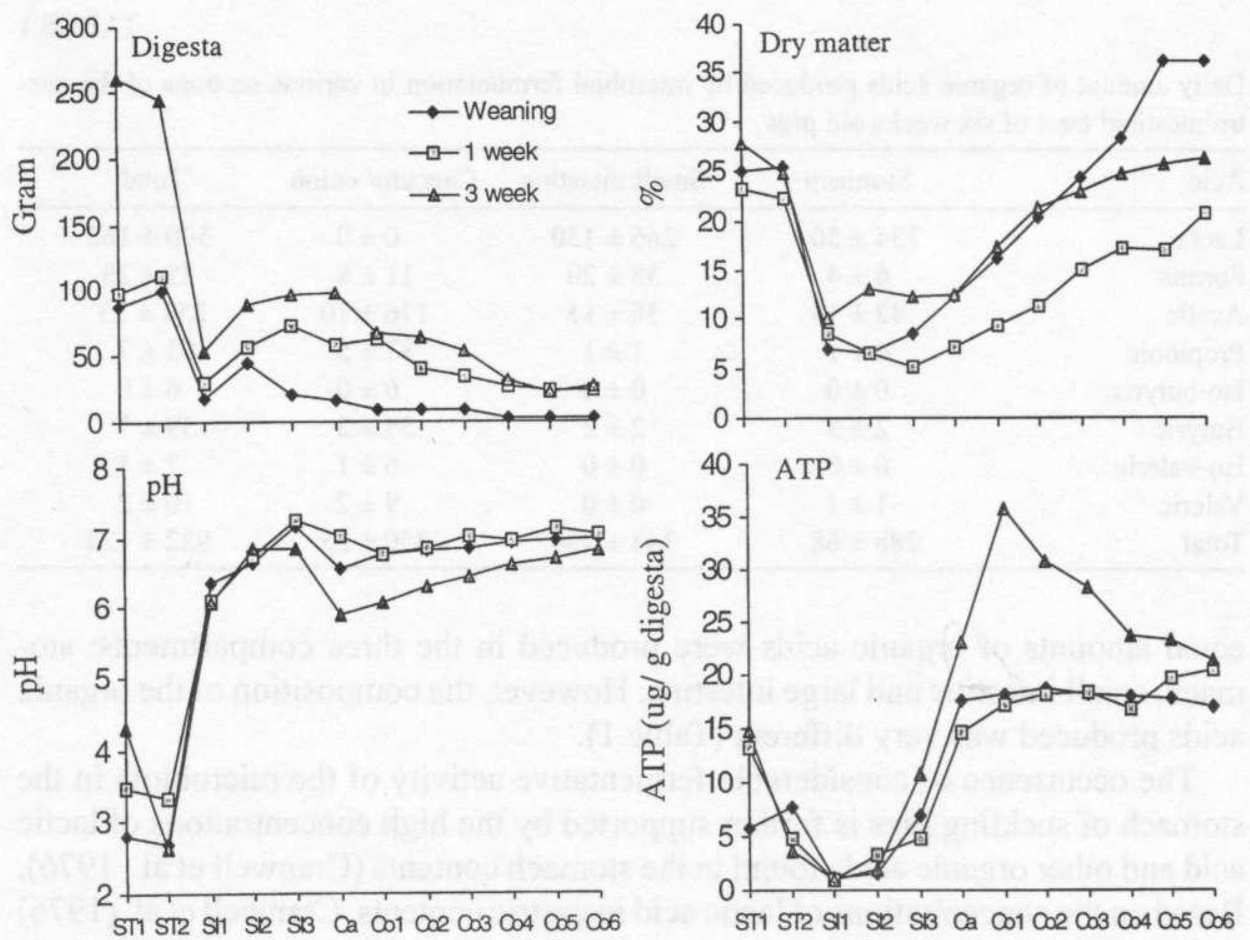

Gut segment

Figure 4. Amount of digesta, dry matter content, $\mathrm{pH}$ and ATP-concentration in digesta from various regions of the gastrointestinal tract of pigs sacrificed at weaning (28 days), 6 days postweaning and 20 days postweaning. Each point represents the mean value from 8 pigs

\section{MICROBIAL FERMENTATION IN VARIOUS REGIONS OF THE GASTROIN- TESTINAL TRACT OF YOUNG PIGS}

As shown by Jensen (1988) and Jensen and Jørgensen (1994) substantial microbial activity takes place in the stomach and small intestine of slaughter pigs. From the data presented in Figure 4, this also seems to be the case in young pigs. Vervaeke et al. (1979) have shown that substantial quantities of carbohydrate and protein are fermented in the small intestine of growing pigs. We have quantified the production of organic acids in the gastrointestinal tract of young pigs (Table 1), using short time in vitro incubations (as described by Jensen and Jørgensen, 1994) with gut contents from various regions of the gastrointestinal tract of 6 weeks old pigs (weaned at 4 weeks). It is evident that pronounced microbial fermentation occurs in the stomach and small intestine. In fact, on a molar basis, approximately 
TABLE 1

Daily amount of organic acids produced by microbial fermentation in various sections of the gastrointestinal tract of six weeks old pigs

\begin{tabular}{lcccc}
\hline Acid & Stomach & Small intestine & Caecum/ colon & Total \\
\hline Lactic & $234 \pm 50$ & $266 \pm 130$ & $0 \pm 0$ & $500 \pm 162$ \\
Formic & $6 \pm 4$ & $38 \pm 20$ & $11 \pm 8$ & $55 \pm 23$ \\
Acetic & $42 \pm 18$ & $36 \pm 15$ & $176 \pm 10$ & $254 \pm 23$ \\
Propionic & $4 \pm 1$ & $1 \pm 1$ & $87 \pm 5$ & $92 \pm 7$ \\
Iso-butyric & $0 \pm 0$ & $0 \pm 0$ & $6 \pm 0$ & $6 \pm 0$ \\
Butyric & $2 \pm 3$ & $2 \pm 2$ & $54 \pm 3$ & $59 \pm 7$ \\
Iso-valeric & $0 \pm 0$ & $0 \pm 0$ & $6 \pm 1$ & $7 \pm 1$ \\
Valeric & $1 \pm 1$ & $0 \pm 0$ & $9 \pm 2$ & $10 \pm 2$ \\
Total & $288 \pm 68$ & $343 \pm 100$ & $350 \pm 23$ & $982 \pm 124$ \\
\hline
\end{tabular}

equal amounts of organic acids were produced in the three compartments: stomach, small intestine and large intestine. However, the composition of the organic acids produced was very different (Table 1).

The occurrence of considerable fermentative activity of the microbiota in the stomach of suckling pigs is further supported by the high concentrations of lactic acid and other organic acids found in the stomach contents (Cranwell et al., 1976). Based on the concentrations of lactic acid in gastric contents, Cranwell et al. (1976) estimated that up to half of the lactose in sow's milk underwent bacterial fermentation in the stomach of suckling piglets.

\section{IMPACT OF VARIOUS GROWTH PROMOTING FEED ADDITIVES ON THE MICROBIAL ECOLOGY IN THE GASTROINTESTINAL TRACT}

The primary effect of growth promoting feed additives is to increase growth rate and/or feed conversion efficiency in healthy animals fed a balanced diet adequate in all known nutrients. However, experience from practical pig farming in Denmark indicates that the use of growth feed additives especially antibiotics, copper and zinc oxide also reduces the incidence of diarrhoea.

\section{ANTIBIOTICS}

As reviewed by Armstrong (1986) inclusion of growth promoting antibiotics into pig feed improves liveweight gain by $5-6 \%$ and feed conversion efficiency by $3-4 \%$. The most pronounced effects are found with young animals. The mechanisms by which growth promoting antibiotics improve growth performance are 
not known with certainty, but several theses have been proposed: 1 . nutrients are more efficiently absorbed because of a thinner small intestinal epithelium; 2 . nutrients are spared due to a reduction in competing microorganisms; 3 . microorganisms responsible for subclinical infections are reduced or eliminated; 4 . production of growth-depressing toxins or metabolites by the gastrointestinal microbiota is reduced; 5. microbial deconjugation of bile salts is reduced. Although statistically significant differences in growth rate have never been well correlated with differences in bacterial counts, cither in specific intestinal segments or in the intestine as a whole, several investigations have shown that growth promoting antibiotics do produce significant changes in selective bacterial populations in the gut (Decuypere et al., 1973; Jensen, 1988; Pedersen et al., 1998) and in the metabolic activity of the microbiota (Direck et al., 1986; Jensen, 1988; Pedersen et al., 1998). A review of the literature strongly indicates that growth promoting antibiotics, at the concentrations allowed to be used in pig feed in the EU, accomplish their effect in the small intestine while they have little or no effect on the microbiota in the large intestine. It is generally accepted that the microbiota in the small intestine competes with the host animal for easily digestible nutrients and at the same time produces toxic compounds. Experiments with slaughter pigs have shown that as much as $6 \%$ of the net energy in the pig diet could be lost due to microbial fermentation in the small intestine (Vevaeke et al., 1979; Henderickx et al., 1982). On the other hand, the microbiota in the hindgut is believed to have a beneficial effect on the host animal since it produces energy by fermentation of feed material that has escaped digestion in the small intestine. Jensen et al. (1998) have calculated that on a normal Danish pig diet, $16.4 \%$ of the total energy supply for slaughter pigs is achieved by microbial fermentation in the hindgut. Zincbacitracin, Virginiamycin and Salinomycin have all been shown to reduce microbial activity in the small intestine of slaughter pigs (Jensen, 1988; Jensen, unpublished; Pedersen et al., 1998), while Virginiamycin, Spiramycin and Salinomycin have been shown to reduce microbial fermentation of carbohydrates in the small intestine (Vervaeke et al., 1989; Pedersen et al., 1998). Quantification of the results from these experiments indicates that the amount of energy saved to the animal by the reduced microbial fermentation in the small intestine almost equals the improved feed conversion. Virginiamycin, Spiramycin and Carbadox have also been shown to decrease deamination of amino acids in the small intestine of pigs. Further, it has been shown that Virginiamycin increases apparent protein digestion in the small intestine (Jørgensen and Just, 1988). It has also been shown that addition of antibiotics to pig diets increases ileal digestibility of fat (Jørgensen and Just, 1988). Most of the results mentioned above were carried out with growth promoting antibiotics that are active against Gram positive bacteria such as lactic acid bacteria. However, very few studies have dealt with the effect of Tylosin, an antibiotic that is also active against some Gram negative bacteria, such as Campolybacter and 
Serpulina, on the microbiota in the gastrointestinal tract of pigs. Gedek et al. (1982a) and Jensen (unpublished results) were unable to find any effect of Tylosin on the composition of the microbiota in the gastrointestinal tract of young pigs.

Since the introduction of antibiotics as growth promoters in animal production in the 1950s there has been great concern about the development of resistant bacteria. In Denmark the use of the antibiotic Avopacin as a growth promoter in animal feed has been associated with an increase in resistance to therapeutic agents and a fear that this could reduce the possibility to treat human diseases. This has caused an increased awareness of the use of antibiotics in animal production and a general wish to reduce the use of antibiotics as growth promoters.

\section{PRO- AND PREBIOTICS}

Probiotics (live microbial feed supplements) have, during the last two centuries, often been suggested to improve the ecosystem in the gastrointestinal tract of pigs. However, although the idea behind the probiotic concept is fascinating a review of the literature indicates that the effect of the probiotic preparations currently used is rather speculative. Several investigations have shown that it is very difficult for the microorganisms used as probiotics to establish themselves in the dynamic gut ecosystem of monogastric animals. It seems that probiotics must be delivered with the feed each day.

One possible explanation for the poor and inconclusive results obtained with probiotics may be due to the narrow selection of microbiological types that have been used as probiotics. The types most frequently used are: lactobacilli, bifidobacteria, enterococci, E. coli, bacilli and yeasts. With the possible exception of lactobacilli in young piglets, none of those species are predominant among the indigeneous microbiota in the gastrointestinal tract of pigs. One must assume that the predominant members of the indigeneous microbiota would be a better choice for inclusion in probiotic preparations. Lee (1985) discussed this paradox and suggested that the bacterial species included in probiotic preparations are chosen mainly for historical reasons and because they are easy to culture. It must be pointed out, however, that there is no ecological or scientific basic for the narrow choice of bacterial species currently utilised in probiotic preparations. Strong arguments can in fact be made for the inclusion of many other species. As reviewed by Freter (1992) strong evidence indicates that probiotics containing only one (or a few) bacterial strains will face severe theoretical limitations to their brood and predictable effectiveness. It seems more realistic to use complex mixtures of bacteria resembling the indigeneous microbiota as probiotics.

Another important comment to the work carried out with probiotics is that in most cases where a beneficial nutritional effect was found, the performance values 
of the control groups were themselves low. Whether this indicates purely biological variation between the control and treated groups or a real improvement under poor management is unclear. This may be significant because one area where probiotics may be of real value is where poor management or other conditions result in poor performance. More studies should be carried out in this area.

In general, one must expect the use of probiotics to have their biggest effect when the host animal is without a stable microbiota; that means just after birth, around weaning, after movement to a new environment or after antibiotic therapy.

An alternative to supplementing gut microbiota with microbials added to the diet, is to encourage the growth of (selected) strains of the indigeneous microbiota which have been identified as having beneficial properties on the host animal. The most effective way of achieving this is by incorporation of compounds in the diet which survive passage through the stomach and small intestine and selectively stimulate selected bacteria in the hind gut. Carbohydrates, in particular non starch polysaccharides, are the principal energy substrate for large intestinal fermentation in pigs (Bach Knudsen et al., 1991, 1993; Jensen and Jørgensen, 1994; Jensen et al., 1998). Specific carbohydrates, especially sugar alcohols and oligosaccharides that pass undegraded to the colon have been used to influence the composition of the microbiota in the large intestine. Unlike other indigestible sugars such as lactose, which is hydrolysed by a variety of gut bacteria, these sugar alcohols and oligosaccharides are only fermented by a limited range of microorganisms and as such, in theory at least, should be able to selectively stimulate the growth of selected microorganisms. Several investigators have shown that specific carbohydrates are in fact able to change the composition of the microbiota and to decrease the concentration of ammonia and putrefactive products in the hind gut of man and monogastric animals (Gibson and Roberforid, 1994; Jensen and Jensen, 1998). However, their beneficial consequences on growth performance have yet to be conclusively demonstrated.

Apart from stimulating the growth of selected microorganisms several specific carbohydrates are also known to be able to block the binding of some potentially pathogenic bacteria to the gut epithelium (Chesson, 1994; Mul and Perry, 1994).

\section{COPPER}

Several investigations have shown that the addition of high levels of $\mathrm{Cu}$ to the diets of young pigs increases their growth performance. However, the mechanism by which this feed additive functions is not well understood. Its action has been attributed to its antimicrobial activity. However, surprisingly few studies have been conducted to investigate the effect of high levels of $\mathrm{Cu}$ on the microbiota in the gastrointestinal tract of pigs. Fuller (1960) found that in pigs fed copper sulphate the numbers of lactobacilli and coliform organisms remained unaffected, but there 
was a marked fall in the number of streptococci. The extent of the reduction varied but the counts of streptococci in the treated pigs were always lower than in the control pigs and the reduction could be as much as from $10^{9}$ to $10^{3}$ counts per $\mathrm{g}$ faeces. These findings are in agreement with the results of Dunning et al. (1998) that streptococci are susceptible to copper under anaerobic conditions while most lactobacilli and $E$. coli are insensitive. Copper is also known to cause inactivation of a variety of viruses under anaerobic conditions (Sagriponti et al., 1993). Kellog et al. (1964) reported that copper sulphate $(250 \mathrm{ppm})$ decreased the counts of lactobacilli and total anaerobes in faeces. Feeding different types of feed additives to pigs, Kellog et al. (1964) found that there was, in general, an apparent inverse relationship between growth performance of the pigs and the total counts of lactobacilli, streptococci and total anaerobes in their faeces. According to Varel et al. (1987) copper sulphate reduces the number of ureolytic organisms in pig faeces, with a marked decrease occurring in the Streptococcus spp., which made up $74 \%$
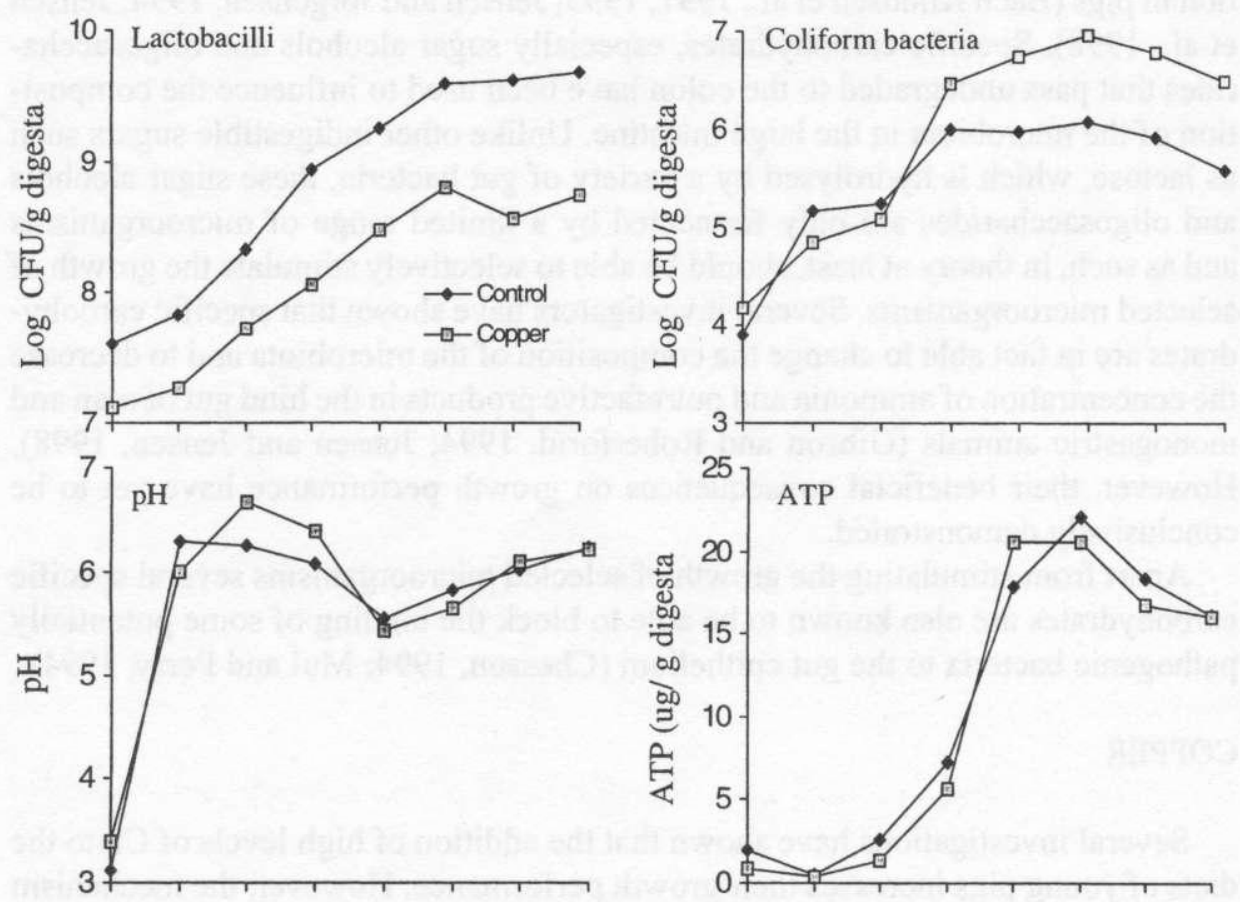

ST Sl1 SL2 S13 Cae Co1 Co2 Rec

\section{ST Sl1 SL S13 Cae Co1 Co2 Rec}

Gut segment

Figure 5. Density of lactobacilli and coliform bacteria, $\mathrm{pH}$ and ATP-concentration in various regions of the gastrointestinal tract of pigs fed a low (12 ppm) and high $(170 \mathrm{ppm})$ copper supplemented diet, respectively. Each point represents the mean value from 6 pigs 
of the ureolytic isolates from the pigs on the basal diet. Copper sulphate was further shown to reduce faccal urcase activity. Using ileal content and in vitro incubations Henderickx et al. (1982) found that copper sulphate strongly inhibits the evolution of the number of streptococci and lactobacilli and the production of organic acids. In accordance with these findings we have also found that copper affects the composition and activity of the microbiota in the gastrointestinal tract of weaned pigs (Figure 5).

Evidence that copper accomplishes its growth promoting effect through the microbiota is further supported by the results of Shurson et al. (1990), which showed that high $\mathrm{Cu}(283 \mathrm{ppm})$ tends to increase daily growth rate and feed conversion rate in conventional pigs but decreases them in germ-free pigs. Shurson et al. (1990) also found that high $\mathrm{Cu}$ generally reduces villus height and width and crypt depth in germ-free pigs, whereas it increases these parameters in conventional pigs. 250 ppm $\mathrm{Cu}$ (as copper sulphate) has also been shown to stimulate intestinal lipase and phospholipase $\mathrm{A}_{2}$ activities, leading to an improvement of dietary fat digestibility in weaning pigs (Luo et al., 1996), and to increase protein utilisation, most probably through activation of pepsin activity (Kirschgessner et al., 1976). These findings are in agreement with investigations with growth promoting antibiotics which have also been found to increase fat and protein digestibility. In this respect it is also interesting that Feighner and Dashkevicz (1987) reported an inverse relationship between microbial deconjugation of bile salts in the small intestine and growth performance in chickens and that growth promoting antibiotics decrease the deconjugation of bile salts. Conjugated bile salts aid in digestion, emulsification and absorption of fats and lipids from the small intestine.

\section{ORGANIC ACIDS (FERMENTED FEED)}

A postweaning lag, characterised by poor growth, general unfitness and often by scouring is usually observed in the first week after weaning of 3 to 4 week old pigs. This postweaning lag phase may have lasting detrimental effects on performance and may be related to the inability of the weaning pig to secrete sufficient quantitics of hydrochloric acid in the stomach to lower gastric $\mathrm{pH}$, in order to properly digest the feed and to inhibit the proliferation of detrimental bacteria (Cranwell et al., 1976). Improvements in postweaning growth rate and the efficiency of feed utilisation by organic acids have been achieved in several investigations. This literature has been recently summarized in the review papers by Ravindran and Kornegay (1993) and Gabert and Sauer (1994); fumaric, citric and formic acids have been the most widely investigated of the organic acids. Organic acids are known to have antibacterial activity (Cherrington et al., 1991), to improve intestinal absorption of minerals (Ravindran and Kornegay, 1993), to enhance the 
digestibility of phosphate (Jongbloed and Jongbloed, 1996), to improve the apparent ileal digestion of protein and amino acids and to decrease amine concentration in gut content (Mosenthin et al., 1992).

A few studies have attempted to correlate changes in the gastrointestinal ecosystem in response to diet acidification. Risley et al. (1991, 1992), were unable to detect any change in $\mathrm{pH}$ or in the population of lactobacilli and E. coli along the entire gastrointestinal tract in weaned piglets fed either $1.5 \%$ fumaric or citric acid. Similar results were observed by Gabert (1994). Risley and Kornegay (1990) also found that the addition of fumaric and citric acids did not modify the effects of postweaning challenge to $E$. coli. In contrast, Sutton et al. (1991) reported that fumaric acid decreased the number of $E$. coli in the stomach while Gedek et al. (1992a) observed a decrease of several enteric bacteria including $E$. coli in the gastrointestinal tract of weaned piglets fed a diet supplemented with fumaric acid. In general, however, it must be concluded that the evidence for a lowering of gastric $\mathrm{pH}$ and a reduction in the population density of coliform in the gastrointestinal tract by adding fumaric or citric acid to pig starter diets is rather weak. For formic acid there is some evidence in the literature that it decreases $\mathrm{pH}$ and the population density of coliform bacteria in the gastrointestinal tract. Bolduan et al. (1988) and Jensen (unpublished) have shown that formic acid reduces the $\mathrm{pH}$ in the stomach. Furthermore, Bolduan et al. (1988), Kirchgessner et al. (1992) and Jensen (unpublished) found that formic acid decreases the population of coliform bacteria in the stomach and small intestine of weaned piglets. However, Gedek et al. (1992b) did not find any changes in the population of coliform bacteria in the small intestine when weaned piglets were fed formic acid. Similarly, the effect of propionic acid on the gastrointestinal ecosystem is also inconsistent. Cole et al. (1968) reported that propionic acid reduced the population of coliform bacteria in the small intestine and Bolduan et al. (1988) reported that it decreased the population of coliform bacteria in the stomach. However, Mathew et al. (1991) and Sutton et al. (1991) did not observe any effect of supplementation with propionic acid on coliform bacteria in the gut of weaned piglets.

In contrast to the other organic acids the results obtained with lactic acid on the gastrointestinal ecosystem are more consistent. White et al. (1969) were able to reduce gastric $\mathrm{pH}$ by 1 unit using a milk-based liquid diet acidified to $\mathrm{pH} 4.8$ with lactic acid. A corresponding reduction in haemolytic coliform bacteria and in duration of scour were observed. Furthermore, Ratcliffe et al. (1986) showed that feeding milk acidified with $1 \%$ lactic acid significantly reduced gastric $\mathrm{pH}$ and coliform count throughout the gastrointestinal tract in pigs weaned at two days of age. Using gastric cannulated pigs, Thomlinson and Lawrence (1981) found that addition of $1 \%$ lactic acid to the drinking water of creep fed piglets significantly decreased the mean gastric $\mathrm{pH}$, measured at hourly intervals, from 4.03 to 3.44 . Thomlinson and Lawrence (1981) further reported that $1 \%$ lactic acid delayed the 
multiplication of enterotoxigenic $E$. coli and lowered the mortality rate. Earlier studies with lactic acid treated drinking water had also shown favourable responses in terms of coliform numbers and subsequent health and performance (Kershaw et al., 1966; Cole et al., 1968). In a recent study (Mikkelsen and Jensen, unpublished) it was found that addition of high concentrations of lactic acid to a mixture of feed and drinking water significantly reduced $\mathrm{pH}$ in the stomach, increased lactobacilli and yeast and decreased coliform bacteria in the entire gastrointestinal tract of growing pigs. Similar effects were found when weaned piglets were fed fermented liquid feed characterised by a high concentration of lactic acid (Jensen and Mikkelsen, 1998). Although, lactic acid decreases gastric $\mathrm{pH}$ it does not decrease $\mathrm{pH}$ in the small intestine, in fact in some cases an increased $\mathrm{pH}$ has been detected in the small intestine. Therefore, it appears that the secretion of $\mathrm{HCO}_{3}^{-}$ from the pancreas overcame the additional acid load from the diet. That is supported by some preliminary results from our Institute which indicate that lactic acid stimulates pancreatic secretion. Furthermore, lactic acid has been reported to stimulate intestinal motility in rats, in vitro (Yokokura et al., 1977).

The use of water as a vehicle for delivering organic acids, in particular lactic acid, appears to have given more consistent advantages than diet acidification. As pointed out by Patridge (1993) the two methods have unfortunately never been evaluated within the same study. Because the volume of water intake is about 2.5 fold higher than feed intake, and especially because newly weaned piglets take in high amounts of water, water acidification provides a greater scope for delivering higher and more regular dose of acids to piglets. The benefits of adding organic acids, however, should be weighed against their cost-effectiveness and handling characteristics. The cost of adding these additives generally tends to be higher than the improvements obtained. In addition, the corrosive nature of organic acids to farm equipment will be a major constraint for their routine use.

From the data presented above, it is obvious that it is not entirely clear how organic acids enhance gut health. A number of explanations have been put forward including those concerning $\mathrm{pH}$ and its effect on reducing coliform counts. In fact, Kovacs et al. (1972) found a negative correlation between gastric $\mathrm{pH}$ and coliform bacteria. Lactic acid, especially, has been shown to have bacteriostatic activity against potentially pathogenic bacteria such as E. coli and Salmonella spp. (Nout et al., 1989). In addition, lactic acid may create a gut milieu favourable for the growth of yeast, and it is well known that yeast cells may bind some potentially pathogenic bacteria such as $E$. coli and salmonella to their cell walls and thus block the binding of these pathogenic bacteria to the gut epithelium (Mull and Perry, 1994).

An alternative to the use of organic acids in pig diets will be the use of fermented feed.. Fermented liquid feed is characterised by high numbers of lactic acid bacteria, high numbers of yeast, a low $\mathrm{pH}$ and a high concentration of lactic acid 
(Smith, 1976; Russel et al., 1996; Mikkelsen and Jensen, 1997; Jensen and Mikkclsen, 1998). Fermented liquid feed has been shown to improve the growth performance of piglets (Smith, 1976; Geary et al., 1996; Russel et al., 1996) and to change the microbiota in the intestinal tract (Mikkelsen and Jensen, 1997; Jensen and Mikkelsen, 1998). Furthermore, case-control analyses of Danish pig herds have demonstrated that Salmonella infections are less prevalent in herds fed liquid feed compared to herds fed dry feed (Dahl, 1997).

\section{CONCLUSIONS}

A stable gut ecosystem has a substantial capacity to resist change, largely because existing micro-habitats within the gut ecosystem are fully occupied and available energy sources rapidly utilised. It is extremely difficult to introduce additional new organisms into this complex population unless the existing microbiota is greatly disturbed or additional nutrients are provided to selectively support the exogenous strains.

As pointed out by Chesson (1994), any productive increase shown by pigs, after feeding intestinal mediators, requires a concomitant increase in nutrient availability to the host animal to fuel the response shown. This need could be met by an absolute increase in the amount of nutrients absorbed, by nutrient sparing or by better utilisation of the nutrients already available to the host. Although the gut only represents a small fraction of the total body mass, it is the single most demanding organ in the body in terms of its need for energy and protein. Thus, any change in the metabolic demands of the gut is likely to have a great impact on the whole animal, and especially the microbial load in the small intestine is likely to affect the host.

In physiological terms the consequences of reducing the microbial load in the small intestine can be summarized as:

- a reduction in protein turnover and energy requirement in the gut as a consequence of lower rates of crypt cell proliferation and reduced gut mass;

- a reduction in protein demand in the liver as a consequence of changed immunological status;

- a reduction in the amount of energy and nitrogen lost due to less mucin secretion;

- an increase in nitrogen, fat and carbohydrate digestion and absorption;

- less energy needed to detoxify ammonia and putrefactive products. 


\section{REFERENCES}

Arbuckle J.B.R., 1968. The distribution of certain Escherichia coli strains in pigs and their environment. Brit Vet. J. 124, 152-159

Armstrong D.C., 1986. Gut-active growth promotors. In: E.A. Buttery (Editor). Control and metabolism of animal growth, pp. 21-37

Bach Knudsen K.E., Jensen B.B., Andersen J.O., Hansen I., 1991. Gastrointestinal implications in pigs of wheat and oat fractions. 2. Microbial activity in the gastrointestinal tract. Brit. J. Nutr. $65,233-248$

Bach Knudsen K.E., Jensen B.B., Hansen I., 1993. Oat bran but not a b-glucan enriched oat fraction enhances butyrate in the large intestine of pigs. J. Nutr. 123, 1235-1247

Bolduan G., Jung H., Schneider R., Block J., Klenke B., 1988. Die Wirkung von Propion- und Ameisensäure in der Ferkelaufzucht. J. Anim. Physiol. Anim. Nutr. 59, $72-78$

Cherington C.A., Hinton M., Mead G.C., Chopra I., 1993. Organic acids: chemistry, antibacterial activity and practical applications. Advan. Microbiol. Physiol. 32, 87-108

Chesson A., 1994. Probiotics and other intestinal mediators. In : D.J.A. Cole, J. Wiseman, M.A. Warley (Editors). Principles of pig science. Nottingham University Press, pp. 197-214

Cole D.J.A., Beal R.M., Luscombe J.R., 1968. The effect on performance and bacterial flora of lactic acid. propionic acid, calcium propionate and calcium acrylate in the drinking water of weaned pigs. Vet. Res. 83, 459-464

Cranwell P.D., Noakes D.E., Hill K.J., 1976. Gastric secretion and fermentation in suckling pig. Brit. J. Nutr. 36, 71-86

Cranwell P.D., 1990. The development of the gastrointestinal microflora in the milk-fed pig and milk fed human infant: A revicw. La Trobe University, School of Agriculture, Occasional paper No. 21 , pp. $1-40$

Dahl J., 1997. Feed-related risk factors for sub-clinical salmonella infections (in Danish). Vet. Inform., December 1997, pp. 17-20

Decuypere J., Henderickx H.K., Vervaeke I., 1973. Influence of nutritional doses of Virginiamycin and Spiramycin on the quantitative and topographical composition of the gastro-intestinal flora of artificially reared piglets. Zbl. Bakt. Hyg., 1. Abt. Orig. A223, 348-355

Dierick N.A., Vervaeke I.J., Decuypere J.A., Henderickx H.K., 1986. Influence of the gut flora and some growth promoting feed additives on nitrogen metabolism in pigs. II. Studies in vivo. Livest. Prod. Sci. 14, 177-193

Dunning J.C., Marquis R.E., 1998. Anaerobic killing of oral streptococci by reduced, transition metal cations. Appl. Environ. Microbiol. 64, 27-33

Feighne S.D., Dashkevicz M.P., 1987. Subtherapeutic levels of antibiotics in poultry feeds and their effects on weight gain, feed efficiency, and bacterial cholyltaurine hydrolase activity. Appl. Environ. Microbiol. 53, 331-336

Freter R., 1992. Factors affecting the microccology of the gut. In: R. Fuller (Editor). Probiotics. The scientific basis. London. Chapman and Hall, pp. 177-193

Fuller R., Newland L.G.M., Briggs C.A.E., Braude R., Mitchell, K.G., 1960. The normal intestinal flora of the pig. IV. The effect of dietary supplements of penecillin, chlortetracyclin or copper sulphate on the faecal flora. J. Appl. Bacteriol. 23, 195-205

Fuller R., Barrow P.A., Brooker B.E., 1978. Bacteria associated with the gastric epithelium of neonatal pigs. Appl. Environ. Microbiol. 35, 582-59l

Gabert V.M., 1994. The effect of supplementation of organic acids, oligosaccharides and lactitol on the digestibility of amino acids and bacterial populations and metabolites in the digestive tract of early-weaned pigs. M. Sc. Thesis. University of Alberta, Edmonton, Canada 
Gabert V.M., Sauer W.C., 1994. The effects of supplementing diets for weanling pigs with organic acids. A review. J. Anim. Feed Sci. 3, 73-87

Gedek B., Roth F.X., Kirchgessner M., Wiehler S., Bott A., Eidelsburger U., 1992a. Zum einfluss von Furmarsäure, Salzsäure, Natriumformiat, Tylosin und Toyocerin auf die Keimzahlen der Mikroflora und deren Zusammensetzung in verschiedenen Segmenten des Gastrointestinaltraktes. J. Anim. Physiol. Anim. Nutr. 68, 209-217

Gedek B., Kirchgessner M., Eidelsburger U., Wiehler S., Bott A., Roth F.X., 1992b. Zum Einfluss von Ameisensäure auf die Keimzahlen der Mikroflora und deren Zusammensetzung in verschierdenen Segmenten des Gastrointestinaltraktes. J. Anim. Physiol. Anim. Nutr. 67, 206-214

Geary T.M., Brooks P.H., Morgan D.T., Campbell A., Russel P.J., 1996. Performance of weaner pigs fed ad libitum with liquid feed at different dry matter concentrations. J. Sci. Food Agric. 72 , $17-24$

Gibson G.R., Roberfroid M.B., 1994. Dietary modulation of the human colonic microbiota: introducing the concept of prebiotics. J. Nutr. 125, 1401-1412

Gleed P.T, Sansom B.F., 1982. Ingestion or iron in sows faeces by piglets reared in farrowing crates with slotted floors. Brit. J. Nutr, 47, 113-117

Henderickx H.K., Vervaeke I.J., Decuypere J.A., Dierick N.A., 1982. Effect of growth promoting agents on the intestinal gut flora. Advan. Vet. Med. 33, 56-62

Jensen B.B., 1988. Effect of diet composition and Virginiamycin on microbial activity in the digestive tract of pigs. In: L. Buraczewska, S. Buraczewski, B. Pastuszewska, T. Żebrowska (Editors). Proceeding of the 4th Symposium on Digestive Physiology in the Pig. Jabłonna, Poland, pp. $392-400$

Jensen B.B., Jensen, M.T., 1998. Microbial production of skatole in the digestive tract of entire male pigs. In: W.K. Jensen (Editor). Skatole and boar taint, pp. 41-76

Jensen B.B., Jørgensen H., 1994. Effect of dietary fiber on microbial activity and microbial gas production in various regions of the gastrointestinal tract of pigs. Appl. Environ. Microbiol. 60 , 1987-1904

Jensen B.B., Mikkelsen L., Christensen D.N., 1998. Intregration of ileum fistulated pigs and in vitro fermentation to quantify the effect of diet on composition of microbial fermentation in the large intestine. In: H.Jørgensen, J.A. Fernandez (Editors). Proceedings of NJF Seminar No 274 on energy and protein evaluation for pigs in the Nordic countries. NJF report No. 119, pp. 106-110

Jensen B.B., Mikkelsen L.M., 1998. Liquid feed to pigs. In: Recent advances in animal nutrition (in press)

Jongbloed A.W., Jongbloed, R., 1996. The effect of organic acids in diets for growing pigs on enhancement of microbial phytase efficacy. Report ID-DLO No 96009. The Netherlands

Jørgensen H., Just A., 1988. Effect of different dietary compounds on site of absorption/site of disappearance of nutrients. In: L. Buraczewska, S. Buraczewski, B. Pastuszewska, T. Żebrowska (Editors). Proceeding of the $4^{\text {th }}$ Symposium on Digestive Physiology in the Pig. Jabłonna, Poland, pp. 230-239

Kellogg T.F., Hays V.W., Catron D.V., Quinn L.Y., Speer V.C., 1964. Effect of dietary chemotherapeutics on the performance and fecal flora of baby pigs. J. Anim. Sci. 25, 1102-1106

Kershaw G.F., Luscombe J.R., Cole D.J.A., 1966. Lactic acid and sodium acrylate: effect of growth rate and bacterial flora in the intestines of weaner pigs. Vet. Rec. 79, 296

Kirchgessner M., Beyer M.G., Steinhart H., 1976. Activation of pepsin (EC 3.4.4.1) by heavy-metal ions including contribution to the mode of action of copper sulphate in pig nutrition. Brit. J. Nutr. 36, 15-23

Kirchgessner M., Gedek B., Wiehler S., Bott A., Fidelsburger U., Roth F.X., 1992. Zum Einfluss von Ameisensäure, Calciumformiat und Natriumhydrogencarbonat auf die Kiemzhalen der 
Mikroflora und deren Zusammensetzung in verchiedenen Segmenten des Gastrointestinaltraktes. J. Anim. Physiol. Anim. Nutr. 68, 73-81

Kovacs F., Nagy B., Sinkovics G., 1972. The gut bacterial flora of healthy early weaned piglets, with special regard to factors influencing its composition. Acta Vet. Acad. Sci. Hung. 22, 327-338

Lee A., 1985. Neglected niches, the microbial ecology of the gastrointestinal tract. Advan. Microb. Ecol. 8, 115-162

Luo X.G., Dove C.R., 1996. Effect of dietary copper and fat on nutrient utilization, digestive enzyme activities, and tissue mineral levels in weanling pigs. J. Anim. Sci. 74, 188-1896

Mathew A.G., Sutton A.L., Scheidt A.B., Forsyth D.M., Patterson J.A., Kelly D.T., 1991. Effects of a propionic acid containing feed aditive on performance and intestinal microbial fermentation of the weanling pig. In: M.W.A. Verstegren, J. Huisman, L.A. den Hartog (Editors). Proceedings of the $5^{\text {th }}$ International Symposium on Digestive Physiology in Pigs. Wageningen, The Netherlands, pp. 464-469

Mikkelsen L.L., Jensen B.B., 1997. Effect of fermented liquid feed (FLF) on growth performance and microbial activity in the gastrointestinal tract of weaned piglets. In: J.P. Leplace, C. Fevrier, A. Barbean (Editors). Proceeedings of the $7^{\text {th }}$ Symposium on Digestive Physiology in Pigs, Saint-Malo, France. EAAP Publication No. 88

Mosenthin R., Sauer W.C., Ahrens F., de Lange C.F.M., Bornholdt U., 1992. Effect of dietary supplements of propionic acid, siliceous earth or a combination of these on the energy, protein and amino acid digestibilities and concentrations of microbial metabolites in the digestive tract of growing pigs. Anim. Feed Sci. Technol, 37, 245-255

Nout M.J.R., Rombouts F.M., Havelaar A., 1989. Effect of accelerated natural lactic fermentation of infant food ingredients on some pathogenic microorganisms. Int. J. Food Microbiol. 8, 351-361

Mul A.J., Perry F.G., 1994. The role of fructo-oligosaccharides in animal nutrition. In: Recent advances in animal nutrition, pp. 54-79

Patridge G.G., 1993. New approaches with pig weaner diets. In: Recent advances in animal nutrition, pp. 221-248

Pedersen A.C., Jensen B.B., Jensen M.S., 1998. Sangrovit and Salocin in feed for slaughter pigs (in Danish). Publication No. 382. The National Committee for Pig Breading, Health and Production, Copenhagen, Denmark

Ratcliffe B., Cole C.R., Fuller R., Newport M.J., 1986. The effect of yoghurt and milk fermented with a porcine intestinal strain of Lactobacillus reuteri on the performance and gastrointestinal flora of pigs weaned at two days of age. Food Microbiol. 3, 203-211

Ravindran V., Kornegay E.T., 1993. Acidification of weaner pig diets: A review. J. Sci. Food Agric. $62,313-322$

Risley C.R., Kornegay E.T., 1990. Effect of an enterotoxigenic Escherichia coli (ETEC) challenge on intestinal digesta measurements in weanling pigs fed organic acids. J. Anim. Sci. 68, Suppl. I, 377

Risley C.R., Kornegay E.T., Lindemann M.D., Weakland S.M., 1991. Effect of organic acids with and without a microbial culture on performance and gastrointestinal tract measurements of weaning pigs. Anim. Feed Sci. Technol. 35, 259-270

Risley C.R., Kornegay E.T., Lindemann M.D., Wood C.M., Eigel W.N., 1992. Effect of feeding organic acids on selected intestinal content measurements at varying times postweaning in pigs. J. Anim. Sci. 70, 196-206

Russell P.J., Geary T.M., Brooks P.H., Campbell A., 1996. Performance, water use and effluent outpul of weaner pigs fed ad libitum with either dry pellets or liquid feed and the role of microbial activity in the liquid feed. J. Sci. Food Agric. 72, 8-16 
Shurson G.C., Ku P.K., Waxler G.L., Yokoyama M.T., Miller E.R., 1990. Physiological relationship between microbiological status and dietary copper levels in the pig. J. Anim. Sci. 68, 1061-1071

Sagripanti J.-L., Rouston I.B., Lytle C.D., 1993. Virus inactivation by copper or iron ions alone and in the presence of peroxide. Appl. Environ. Microbiol. 59, 4374-4376

Smith P., 1976. A comparison of dry, wet and soaked meal for fattening bacon pigs. Exp. Husbandry $30,87-94$

Sutton A.L., Mathew A.G., Scheidt A.B., Patterson J.A., Kelly D.T., 1991. Effects of carbohydrate sources and organic acids on intestinal microflora and performance of the weanling pig. In: M.W.A. Verstegren, J. Huisman, L.A. den Hartog (Editors). Proceedings of the $5^{\text {th }}$ International Symposium on Digestive Physiology in Pigs. Wageningen, The Netherlands, pp. 442-427

Thomlinson J.R., Lawrence T.L.J., 1981. Dietary manipulation of gastric $\mathrm{pH}$ in the prophylaxis of enteric disease in weaned pigs: Some field observations. Vet. Rec. 109, 120-122

Varel W.H., Robinson I.M., Pond W.G., 1987. Effect of dietary copper sulfate, Aureo SP250, or clinoptilolite on ureolytic bacteria found in the pig large intestine. Appl. Environ. Microbiol. 53, 2009-2012

Vervaeke I.J., Decuypere J.A., Dierick N.A., Henderickx H.K., 1979. Quantitative in vitro evaluation of the energy metabolism influenced by Virginiamycin and Spiramycin used as growth promotors in pig nutrition. J. Anim. Sci. 49, 846-856

White F., Wenham G., Sharman G.A.M., Jones A.S., Rattary E.A.S., McDonald I., 1969. Stomach function in relation to a scour syndrome in the piglet. Brit. J. Nutr. 23, 847-858

Yokokura T., Yajima T., Hashimoto S., 1977. Effect of organic acid on gastrointestinal mobility of rat in vitro. Life Sci. 21, 59-62 